\title{
Competências digitais e as demandas da sociedade contemporânea: diagnóstico e potencial para formação de professores do Ensino Superior da Bahia
}

\section{Digital skills and the demands of contemporary society: diagnosis and potential for teacher training in Higher Education in Bahia}

Competencias digitales y las demandas de la sociedad contemporánea: diagnóstico y potencial para formación de profesores de la Enseñanza Superior de Bahía

Mary Valda Sales ${ }^{1}$ José António Marques Moreira² Márcia Rangel ${ }^{3}$

DOI: http://dx.doi.org/10.20435/serie-estudos.v24i51.1290

Resumo: A proposta de pesquisa em tela pretende mapear e analisar as relações atuais existentes entre os campos investigativos da prática pedagógica dos professores e das tecnologias, mais especificamente a relação entre as práticas experienciadas e vivenciadas nas salas de aula do ensino superior e o "domínio" das tecnologias para formação no contexto universitário. Compreendemos que esse campo de pesquisa em particular - prática pedagógica e as tecnologias - é muito amplo e explorado em diversas vertentes e encaminha diretamente ao uso de tecnologias na educação, na prática pedagógica docente, nos processos formativos de maneira geral. Desse modo, a ampliação acerca do conhecimento do "domínio" tecnológico que o professor do ensino superior possui das tecnologias, ainda é um segmento da pesquisa nesse campo, que necessita de mais investigação. Tendo, pois, como objetivo, avaliar o nível de proficiência digital de professores do Ensino Superior da Bahia, está em curso a presente pesquisa desenvolvida pela Rede Colaborativa

\footnotetext{
${ }^{1}$ Universidade do Estado da Bahia (UNEB), Salvador, Bahia, Brasil.

2 Universidade Aberta, Lisboa, Portugal.

${ }^{3}$ Universidade Federal da Bahia (UFBA), Salvador, Bahia, Brasil.
} 
de Aprendizagem (RCA), estrutura criada pela Universidade Federal da Bahia (UFBA), que procura promover o desenvolvimento das competências digitais dos profissionais da educação e fomentar a convergência de modalidades educacionais. A abordagem metodológica tem um cariz quali-quantitativo, sendo que os resultados da pesquisa permitir-nos-ão definir diferentes trilhas de aprendizagem em função do nível de proficiência diagnosticado.

Palavras-chave: competências digitais; fluência digital; Ensino Superior.

Abstract: This research proposal intends to map and analyze the relationship between pedagogical practices and technologies, most specifically when it is concerned with the practices developed in classroom of undergraduate programs and the domain of technology related to education in the university. We understand that this research field - pedagogical practice and technologies - is vast and explored in very different aspects and direct the use of technologies in education in the pedagogical practice and in all the formative processes. The development of knowledge possessed by educators in the technological domain in higher education is still a research field in need of investigation. Its objective is to evaluate the level of digital proficiency of university teachers in Bahia. This research is conducted in the Collaborative Learning Network created by Bahia Federal University in order to promote the development of digital competences of educators and the convergence of educational modalities. The methodological approach is qualitative and quantitative and the results will allow the definition of learning tracks related to the proficiency level diagnosed.

Keywords: digital competences; digital fluency; Higher Education.

Resumen: La propuesta de investigación busca mostrar y analizar las relaciones entre las prácticas pedagógicas y las tecnologías, en concreto en lo que se refiere a las prácticas desarrolladas en las aulas de estudios universitarios y al dominio de tecnologías relacionadas con la educación en la universidad. Entendemos que este campo de estudio - prácticas pedagógicas y tecnologías - es amplio y ha estudiado aspectos muy diferentes, dirigiendo el uso de las tecnologías en la educación en la práctica pedagógica y en todos los procesos formativos. El desarrollo del conocimiento que los educadores poseen en el ámbito tecnológico de la educación superior es todavía un campo de estudio que necesita ser investigado. El objetivo del presente trabajo es evaluar el nivel de habilidades digitales de los profesores universitarios en Bahía. Esta investigación se realiza en la Red de Aprendizaje Colaborativo creada por la Universidad Federal de Bahía para promocionar el desarrollo de las competencias digitales de los educadores y la convergencia de las modalidades educativas. La aproximación metodológica es cualitativa y cuantitativa y los resultados permitirán la definición de guías de aprendizaje relacionadas con el nivel de competencias digitales diagnosticado.

Palabras clave: competencias digitales; fluencia digital; Enseñanza superior.

\section{INTRODUÇÃO}

A partir do início do atual século XXI, muito se demanda da educação, dos espaços formativos das universidades e daqueles que a constituem como prática e atividade humana. Com o advento das tecnologias, principalmente das tecnologias digitais, professores, estudantes e outros profissionais da educação têm vindo a 
ser convocados a rever suas metodologias, estratégias de acesso e construção do conhecimento, difusão de saberes e informações, da relação estabelecida com o conhecimento científico e, ao mesmo tempo, a rever as práticas e as dinâmicas de ensinar e de aprender no âmbito universitário.

Nesse contexto, são explicitamente postos em tela o entendimento do que é aprender a aprender e do que é ensinar na experiência que foram demarcados por Paulo Freire (2004), no sentido de proporcionar aos professores reflexões e ações de autoavaliação de suas práticas, avaliando suas competências, habilidades e capacidades pedagógicas para o trabalho docente com as tecnologias no contexto educacional de formação no ensino superior, tendo em vista as perspectivas de sua aplicabilidade, possibilidades, usabilidades e potencialidades pedagógicas, didáticas e profissionais.

A sociedade do movimento veloz de expansão das tecnologias digitais, principalmente no que diz respeito aos aspectos da comunicação, acesso a informação, construção e difusão do conhecimento, estabelecimento de comunidades mundiais, constituição de outras formas de cultura e de alteração das estratégias de aprendizagens nos diversos espaços formativos, por conta do advento da internet, constitui-se um campo, ainda, muito próspero para as pesquisas no âmbito da educação, das práticas docentes e das necessidades dos professores para formação diante dessa realidade.

Nesse sentido, o crescente desenvolvimento tecnológico traz consigo diversas linguagens como possibilidades para os processos comunicacionais e informacionais humanos, o que, na última década, é muito discutido, pesquisado e estudado no Brasil, em todos os espaços sociais, inclusive os educacionais. Esse contexto apresenta para o campo do ensino superior um quadro de referência contraditória e complexa, visto que, para o desenvolvimento da educação superior pública nacional, ainda não existem as condições estruturais e tecnológicas adequadas, no entanto existem práticas que lidam com essa realidade a partir de outras possibilidades e metodologias alternativas que se mostram eficientes. Os processos de ensinar e aprender nesse contexto precisam ser dinâmicos, convergentes, abertos, flexíveis e híbridos no modo de coexistência entre o tradicional e o moderno, no que se refere às tecnologias de informação e comunicação (TIC) e, é nesse sentido, que buscamos o desenvolvimento desta pesquisa no âmbito do Ensino Superior (ES). 
Acrescente-se, ainda, que os estudos sobre o perfil tecnológico de professores e de estudantes do ES para o domínio e uso efetivo das TIC, em especial, as tecnologias digitais, ainda são muito generalistas e elementares, especialmente no que se refere às atuais condições de atuação docente e às exigências curriculares do ES, posto que os desafios colocados pelas TIC, no seu formato e funcionamento digital conectado ou não, constituem-se em demandas curriculares práticas e teóricas diferentes e complexas nos mais diversos campos da formação universitária.

Assim, se constitui como demanda urgente identificar o nível de fluência digital e as competências tecnológicas dos professores do ES, com o objetivo de se constituírem propostas e políticas de formação que atendam as especificidades de formação (científica, curricular, pedagógica e tecnológica) a partir das realidades dos contextos próprios de cada área, campo de atuação desses docentes no espaço universitário, bem como das exigências de formação postas pelos currículos dos cursos universitários e pela sociedade de maneira geral.

Com efeito, nos últimos dez anos, as propostas de formação de professores para inserção e uso de tecnologias no contexto escolar, nas práticas educativas, são muitas, mas com o foco mais direto na usabilidade e não na eficiência e na exploração pedagógica dessas tecnologias. Desse modo, constituímos esta pesquisa acerca da fluência e competência digital dos professores do ES, no seio da recente Rede Colaborativa de Aprendizagem (RCA $)^{4}$, criada pela Universidade Federal da Bahia (UFBA), que tem, justamente, como um dos seus principais objetivos, promover o desenvolvimento das competências digitais dos profissionais da educação.

A RCA é uma rede constituída por atores da Universidade Federal da Bahia e atores de instituições parceiras, que se articulam com a RCA através de acordos cooperativos, como é o caso da Universidade do Estado da Bahia (UNEB), da Universidade Federal do Reconcâvo da Bahia (UFRB), da Universidade Aberta (UAb) de Portugal, que visa, sobretudo, dinamizar a pesquisa na área das tecnologias digitais na educação, através do intercâmbio de ideias, estudos e projetos, fazendo convergir as ações de investigação científica desenvolvidas por cada uma destas instituições.

\footnotetext{
${ }^{4}$ Disponível em http://www.rca.ufba.br/
} 
Figura 1 - Rede Colaborativa de Aprendizagem

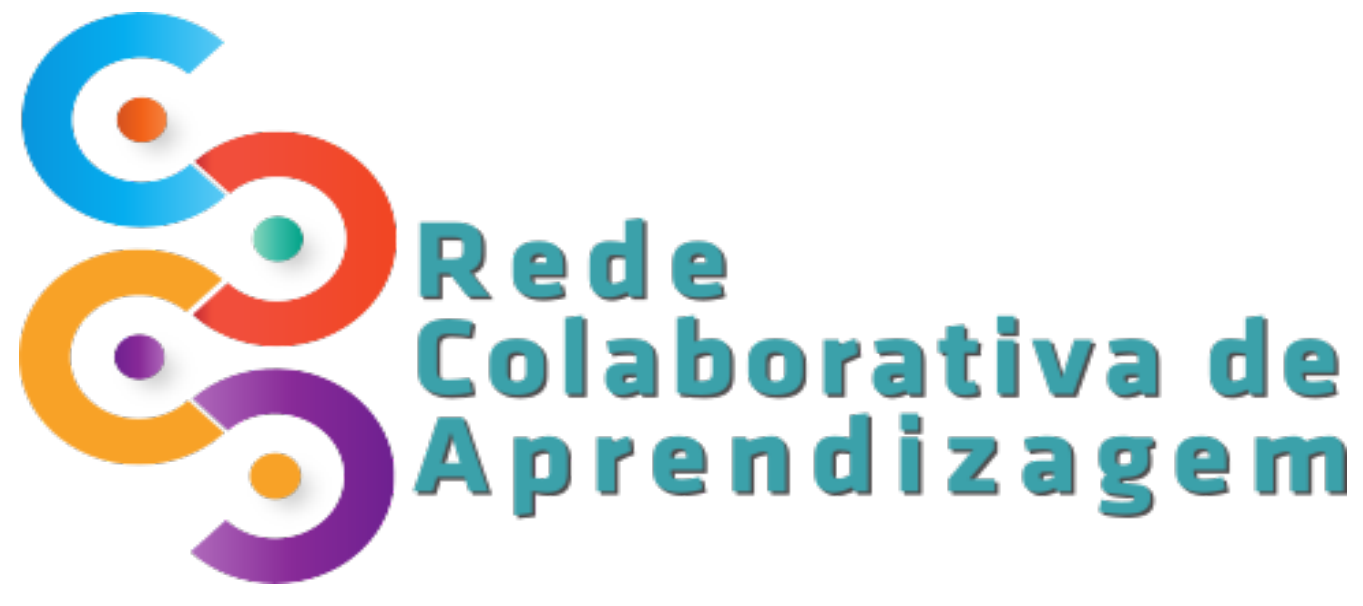

Fonte: SEAD, UFBA (2019).

Para além disso, a RCA possibilita uma ampliação da capacidade de aproveitamento do conhecimento e expertises entre os atores da rede, visando ao compartilhamento interno e externo de conhecimento, metodologias e tecnologias, possibilitando uma melhor otimização do tempo e integração dos espaços acadêmicos e redução de custos com formação continuada de professores e outros profissionais imersos no contexto educacional.

Conhecer o nível de proficiência digital dos professores do ES nos remete a identificar as competências necessárias para uma fluência tecnopedagógica no contexto dos processos de ensino e de aprendizagem, visto que ser competente tecnologicamente não significa apenas fazer uso das tecnologias, sejam elas de informação e comunicação e/ou digitais, mas inseri-las de modo significativo no processo formativo, dando sentido às práticas educativas que possam se fazer colaborativas e autônomas no contexto contemporâneo atual, no qual os sujeitos pertencentes a essa modernidade líquida (BAUMAN, 2001) possam mover-se, alterar suas realidades, dar sentido às suas aprendizagens de forma individual e coletiva, transformando-se e transformando seu espaço formativo e as relações de constituição de comunidades de aprendizagem e/ou de prática (LAVE; WENGER, 1991).

A pesquisa tem sua relevância confirmada se atentarmos no Programme for International Student Assessment ${ }^{5}$ (PISA, 2015), em que se refere que a tecnologia

${ }_{5}^{5}$ Programa Internacional de Avaliação de Alunos (PISA). 
na sala de aula ainda não atingiu os índices de aproveitamento esperados, e no documento Organization for Economic Co-operation and Development ${ }^{6}$ (OECD, 2016), no qual se enfatiza a necessidade de integrar a tecnologia em contexto educativo para apoiar a pedagogia e os ambientes de aprendizagem para o século XXI. A partir de tais pesquisas, entende-se que as tecnologias constituem-se possibilidades efetivas de expandir dramaticamente o acesso ao conhecimento na sociedade em que nos encontramos e, para isso, torna-se necessário que os professores, aqueles que são responsáveis diretos pelo processo educativo/formativo, tenham condições do exercício crítico, criativo e autônomo no que se refere às tecnologias digitais.

Assim, tendo a pesquisa como prática necessária à construção de conhecimento das questões relacionadas aos fazeres educativos de contextos específicos, buscamos aqui indicar questões relevantes que possam nos auxiliar numa compreensão mais ampliada das demandas de formação dos professores e de metodologias de aprendizagem para os estudantes do ES, que possam auxiliar no movimento e na atuação destes na sociedade contemporânea, com condições de exercício da autonomia, liberdade tecnológica e autoria intelectual, política e social.

Isso requer a compreensão do que é necessário para o professor atuar nesse contexto, e "a política e a prática de formação ainda não alcança a real demanda de desenvolvimento de um processo formativo aberto e continuado" (SALES, 2016, p. 222), inclusive no ES.

No entanto ressalta-se que esta pesquisa partirá de um contexto mais amplo, não se direcionando somente pelos pressupostos do campo da formação, mas também considerando os pressupostos das diversas áreas de atuação, das exigências dos diversos currículos para o trabalho docente no ensino superior e da exigência para consolidação das metodologias, práticas e exercícios de ensino para o ensino superior contemporâneo.

\section{COMPETÊNCIAS DOCENTES PARA A INTEGRAÇÃO DAS TDCI NA EDUCAÇÃO: ALGUNS REFERENCIAIS E MODELOS.}

Para viver, aprender e trabalhar bem em uma sociedade cada vez mais digital e conectada, rica em informação e baseada em conhecimento, os estudantes e professores do ES devem usar as tecnologias digitais de forma efetiva, porque,

\footnotetext{
${ }^{6}$ Organização para a Cooperação e o Desenvolvimento Econômico (OECD).
} 
na realidade, em um ambiente educacional qualificado, as tecnologias podem contribuir para que os estudantes se tornem, por exemplo, comunicadores, colaboradores, editores, produtores e, sobretudo, cidadãos informados e responsáveis.

É, pois, essencial que os professores do ES estejam preparados para oferecer essas possibilidades aos estudantes. Tanto os programas de desenvolvimento de profissionais em exercício, como os programas de preparação dos futuros professores devem proporcionar experiências adequadas com tecnologias em todas as fases da formação. Com efeito, os professores em exercício precisam adquirir competências que lhes permitam proporcionar aos estudantes oportunidades de aprendizagem com apoio das tecnologias.

A fim de ajudar a promover melhores processos de aprendizagem mediados pelas tecnologias digitais, várias organizações e centros internacionais, como a Sociedade Internacional para a Tecnologia em Educação (International Society for Technology in Education - ISTE) e a Organização das Nações Unidas para Educação, Ciência e Cultura (United Nation Educational, Scientific and Cultural Organization - UNESCO) têm procurado identificar as necessárias competências docentes a contemplar, em programas de formação e para a inserção, o uso pedagógico das TDIC.

A Sociedade Internacional para a Tecnologia em Educação destaca que a transformação na educação exige repensar as formas como se ensina e se aprende, como já explicitado anteriormente. Para isso, a ISTE criou padrões de competências em tecnologias para estudantes e professores (ISTE, 2008), que a seguir se apresentam, propondo que funcionem como um roteiro para ajudar a repensar os processos educativos nas escolas e nas salas de aula, de acordo com as necessidades da aprendizagem do contexto atual:

1. facilitar e inspirar a aprendizagem e a criatividade dos alunos, ou seja, os professores devem utilizar seu conhecimento da disciplina, da pedagogia e da tecnologia para promover a aprendizagem, criatividade e inovação em ambientes presenciais e virtuais;

2. criar e desenvolver experiências de aprendizagem e avaliação na era digital, ou seja, desenhar, implementar e avaliar experiências autênticas de aprendizagem e avaliação incorporando ferramentas e recursos contemporâneos para maximizar a aprendizagem contextualizada do conteúdo e desenvolver os conhecimentos, habilidades e atitudes descritas nos critérios ISTE para estudantes;

3. exercer o trabalho e aprendizagem na era digital, ou seja, demonstrar conheci- 
mentos, habilidades e processos de trabalho que representem um profissional inovador em uma sociedade global e digital, tais como, demonstrar fluência em sistemas tecnológicos, colaborar com estudantes, colegas e membros da comunidade utilizando ferramentas digitais, comunicar informações relevantes através de uma diversidade de mídias, modelar e facilitar o uso eficaz de ferramentas digitais para localizar, analisar, avaliar e utilizar recursos de informação para apoiar a pesquisa e a aprendizagem;

4. promover a cidadania e responsabilidade digital, isto é, compreender questões sociais, responsabilidades locais e globais em uma cultura digital em evolução, demonstrando comportamento ético e legal nas suas práticas profissionais;

5. engajar-se em atividades de crescimento profissional e liderança, isto é, buscar melhorar continuamente a sua prática profissional, demonstrando aprendizagem ao longo da vida e liderança em sua instituição e comunidade profissional, ao promover e demonstrar o uso eficaz de ferramentas e recursos digitais.

Mais recentemente, em 2017, essa organização realizou uma atualização dessas competências, definindo sete macrocompetências, as quais se apresentam no quadro abaixo.

Quadro 1-Competências definidas pela ISTE para professores

\begin{tabular}{l|l}
\hline APRENDIZ & $\begin{array}{l}\text { O professor aprimora suas práticas continuamente por meio da } \\
\text { aprendizagem colaborativa e da exploração de práticas que utilizam } \\
\text { a tecnologia para melhorar a aprendizagem dos alunos. }\end{array}$ \\
\hline LíDER & $\begin{array}{l}\text { O professor busca oportunidades de liderança para apoiar o empo- } \\
\text { deramento e o sucesso dos alunos e melhorar o processo de ensino } \\
\text { e aprendizagem. }\end{array}$ \\
\hline CIDADÃO & $\begin{array}{l}\text { O professor inspira os alunos a contribuírem de forma positiva e par- } \\
\text { ticiparem de forma responsável do mundo digital. }\end{array}$ \\
\hline COLABORADOR & $\begin{array}{l}\text { O professor se dedica a colaborar tanto com seus colegas como com } \\
\text { seus alunos para melhorar suas práticas, descobrir e compartilhar } \\
\text { recursos e ideias, e resolver problemas. }\end{array}$ \\
\hline DESIGNER & $\begin{array}{l}\text { O professor desenvolve projetos originais com atividades e ambien- } \\
\text { tes orientados aos alunos, reconhecendo a sua diversidade. }\end{array}$ \\
\hline FACILITADOR & $\begin{array}{l}\text { O professor promove a aprendizagem com tecnologias para ajudar } \\
\text { Os alunos a atingirem as competências definidas nos Padrões ISTE } \\
\text { para Estudantes. }\end{array}$ \\
\hline ANALISTA & $\begin{array}{l}\text { O professor entende e usa dados para direcionar suas orientações } \\
\text { e apoiar os alunos na conquista de seus objetivos de aprendizagem. }\end{array}$ \\
\hline
\end{tabular}

Fonte: ISTE (2017). 
Por sua vez, a United Nations Educational, Scientific and Cultural Organization (UNESCO) desenvolveu uma proposta de Padrões de Competência em TIC para Professores (ICT-CST), destacando que os professores, para além da necessidade de possuírem competências em TDIC e poderem trabalhar com tecnologia em sala de aula, precisam ser capazes de ampliar essa utilização visando assegurar novas oportunidades de aprendizagens para os estudantes. Combinando as habilidades das TDIC com as visões emergentes na pedagogia, no currículo e na organização educacional, os padrões foram elaborados para o desenvolvimento profissional dos professores que utilizarão as habilidades e os recursos de TIC para aprimorar o ensino e cooperar com os colegas (UNESCO, 2008). O objetivo geral do projeto não se restringe apenas à melhoria da prática docente, mas, pretende sobretudo, contribuir para o desenvolvimento de um sistema educativo de maior qualidade, para a redução da pobreza e da desigualdade, aumentar o padrão de vida e preparar os cidadãos para os desafios do século XXI.

Mais especificamente, os objetivos desse projeto da UNESCO são:

- constituir um conjunto comum de diretrizes, que os provedores de desenvolvimento profissional podem usar para identificar, construir ou avaliar materiais de ensino ou programas de treinamento de docentes no uso das TDIC para o ensino e aprendizagem;

- oferecer um conjunto básico de qualificações, que permita aos professores integrarem as TDIC no processo de ensino e aprendizagem, para o desenvolvimento do aprendizado;

- expandir o desenvolvimento profissional dos docentes para melhorar suas habilidades em pedagogia, colaboração e liderança, usando as TDIC;

- harmonizar diferentes pontos de vista e nomenclaturas em relação ao uso das TDIC na formação dos professores.

A proposta está organizada em três abordagens diferentes, isto é, em três etapas sucessivas de formação do professor. A primeira é a Alfabetização Tecnológica, que trabalha a utilização de TDICs pelos estudantes para que possam aprender de forma mais eficiente. A segunda é o Aprofundamento do Conhecimento, que está relacionado a desenvolver, em profundidade, conhecimentos sobre os conteúdos programáticos e, com isso, resolver problemas complexos do mundo real. A terceira é a Criação de Conhecimento, que se propõe, com o trabalho do professor, capacitar estudantes para que criem novos conhecimentos e colaborem 
transformando a sociedade, tornando-a mais harmoniosa e próspera.

Por outro lado, o projeto de Padrões de Competência em TIC para os Professores aborda seis componentes do sistema de ensino, que incluem a formação em habilidades de TIC como parte de uma abordagem mais ampla à reforma do ensino, que articula as dimensões da política, do currículo e avaliação, da pedagogia, do uso da tecnologia, da organização e administração da escola e do desenvolvimento profissional. A partir disso, conforme a Figura 2, são apresentados dezoito módulos, que representam como essas abordagens podem se manifestar na prática docente.

Figura 2 - Abordagens propostas pela UNESCO para o desenvolvimento de competências TIC para professores

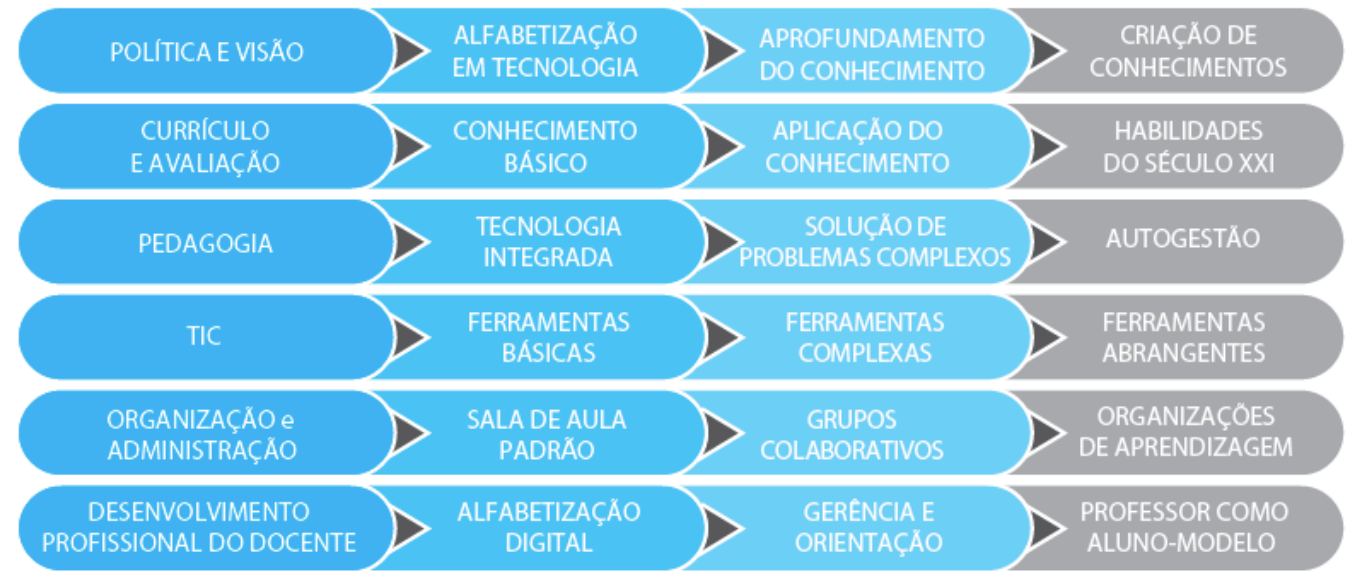

Fonte: UNESCO (2008).

Tendo como base essas duas referências internacionais, o Centro de Inovação para a Educação Brasileira (CIEB) desenvolveu também, recentemente, a Matriz de Competências Digitais CIEB (2019) agrupadas em três áreas: Pedagógica- efetivar o uso das TDIC para apoiar as práticas pedagógicas do professor; Cidadania Digital- usar as TDCI para discutir a vida em sociedade e debater formas de usar a tecnologia de modo responsável; e Desenvolvimento profissional- usar as TDCI para garantir a atualização permanente do professor e o seu crescimento profissional, sendo que estas áreas estão associadas a quatro elementos, conforme se pode ver no quadro 2 . 
Quadro 2 - Competências de professores para o uso das TDIC

\begin{tabular}{|c|c|c|c|c|}
\hline ÁR & \multicolumn{4}{|c|}{ COMPETÊNCIAS } \\
\hline PEDAGÓGICA & \begin{tabular}{l}
\multicolumn{1}{c}{ PRÁTICA } \\
PEDAGÓGICA \\
Ser capaz de \\
incorporar tecno- \\
logia às experiên- \\
cias de aprendiza- \\
gem dos alunos e \\
às suas estratégias \\
de ensino.
\end{tabular} & $\begin{array}{l}\text { Ser capaz de usar } \\
\text { tecnologias digi- } \\
\text { tais para acom- } \\
\text { panhar e orientar } \\
\text { o processo de } \\
\text { aprendizagem } \\
\text { e avaliar o desem- } \\
\text { penho. }\end{array}$ & $\begin{array}{l}\quad \begin{array}{l}\text { PERSONA- } \\
\text { LIZAÇÃO }\end{array} \\
\text { Ser capaz de } \\
\text { utilizar a tecno- } \\
\text { logia para criar } \\
\text { experiências de } \\
\text { aprendizagem } \\
\text { que atendam as } \\
\text { necessidades de } \\
\text { cada estudante. }\end{array}$ & \begin{tabular}{l}
$\quad$ CURADORIA \\
\multicolumn{1}{c}{ E CRIAÇÃO } \\
Ser capaz de se- \\
lecionar e criarre- \\
cursos digitais que \\
contribuam para \\
o processo de \\
ensino e aprendi- \\
zagem e gestão de \\
sala de aula.
\end{tabular} \\
\hline $\begin{array}{l}\text { CIDADANIA } \\
\text { DIGITAL }\end{array}$ & $\begin{array}{l}\text { USO } \\
\text { RESPONSÁVEL } \\
\text { Ser capaz de fazer } \\
\text { e promover o uso } \\
\text { ético e responsá- } \\
\text { vel da tecnologia } \\
\text { (cyberbullying, } \\
\text { privacidade, pre- } \\
\text { sença digital e im- } \\
\text { plicações legais). }\end{array}$ & $\begin{array}{l}\text { USO SEGURO } \\
\text { Ser capaz de fazer } \\
\text { e promover o uso } \\
\text { seguro das tecno- } \\
\text { logias (estratégias } \\
\text { e ferramentas de } \\
\text { proteção de da- } \\
\text { dos). }\end{array}$ & $\begin{array}{l}\text { Ser capaz de fazer } \\
\text { e promover a in- } \\
\text { terpretação crítica } \\
\text { das informações } \\
\text { disponíveis em } \\
\text { mídias digitais. }\end{array}$ & $\begin{array}{l}\text { Ser capaz de } \\
\text { utilizar recursos } \\
\text { tecnológicos para } \\
\text { promover a inclu- } \\
\text { são e a equidade } \\
\text { educativa. }\end{array}$ \\
\hline $\begin{array}{l}\text { DESENVOLVI- } \\
\text { MENTO } \\
\text { PROFISSIONAL }\end{array}$ & $\begin{array}{l}\text { AUTO } \\
\text { DESENVOLVI- } \\
\text { MENTO } \\
\text { Ser capaz de usar } \\
\text { TICs nas ativida- } \\
\text { des de formação } \\
\text { continuada e de } \\
\text { desenvolvimento } \\
\text { profissional }\end{array}$ & $\begin{array}{l}\text { Ser capaz de uti- } \\
\text { lizar as TIC para } \\
\text { avaliar a sua práti- } \\
\text { ca docente e im- } \\
\text { plementar ações } \\
\text { para melhorias. }\end{array}$ & $\begin{array}{l}\text { Ser capaz de } \\
\text { usar a tecnologia } \\
\text { para participar e } \\
\text { promover a parti- } \\
\text { cipação em comu- } \\
\text { nidades de apren- } \\
\text { dizagem e trocas } \\
\text { entre pares. }\end{array}$ & $\begin{array}{l}\text { Ser capaz de uti- } \\
\text { lizar tecnologias } \\
\text { para manter co- } \\
\text { municação ativa, } \\
\text { sistemática e } \\
\text { eficiente com os } \\
\text { atores da comuni- } \\
\text { dade educativa. }\end{array}$ \\
\hline
\end{tabular}

Fonte: CIEB (2019). 
Conforme refere esse organismo, é importante destacar que as matrizes de competências CIEB são apenas um ponto de partida para subsidiar o desenvolvimento de competências digitais de professores, considerando a realidade brasileira, a partir do planejamento de formações voltadas para o uso de tecnologias digitais, e que estas estão sempre sujeitas a modificações, podendo ser aprimoradas a partir das experiências concretas, observadas com o tempo.

De forma semelhante, o Instituto Nacional de Tecnologías Educativas y de Formación del Profesorado (INTEF), em Espanha, desenvolveu o Marco Comum de Competência Digital Docente (INTEF, 2013) no qual apresenta cinco áreas de competência digital para os professores, inspiradas no projeto DIGCOMP ${ }^{7}$ de Carretero, Vuorikari e Punie (2017), conforme descritas abaixo:

1. Informação: identificar, localizar, recuperar, armazenar, organizar e analisar a informação digital, avaliando sua finalidade e relevância.

2. Comunicação: comunicar em ambientes digitais, compartilhar recursos através de ferramentas online, conectar e colaborar com outros através de ferramentas digitais, interagir e participar em comunidades e redes, e desenvolver consciência intercultural.

3. Criação de conteúdos: Criar e editar conteúdos novos (textos, imagens, vídeos), integrar e reelaborar conhecimentos e conteúdos prévios, realizar produções artísticas, conteúdos multimídia e programação informática, saber aplicar os direitos de propriedade intelectual e as licenças de uso de conteúdos digitais.

4. Segurança: promover a proteção pessoal a partir da proteção de dados e da identidade digital.

5. Solução de problemas: identificar necessidades e recursos digitais, tomar decisões ao adotar ferramentas digitais apropriadas, de acordo com o objetivo ou necessidade, resolver problemas conceituais utilizando tecnologias digitais, resolver problemas técnicos, fazer uso criativo da tecnologia, atualizar a própria competência e a de outros.

\footnotetext{
${ }^{7}$ O Quadro Europeu de Competência Digital para Cidadãos, também conhecido por DIGCOMP, é um projeto criado e desenvolvido pelo Joint Research Centre (JRC) que visa identificar os níveis de proficiência digital dos cidadãos europeus. Mais informações em: https://ec.europa.eu/jrc/ en/digcomp
} 
Figura 3 - Áreas do Marco Comum de Competência Digital Docente

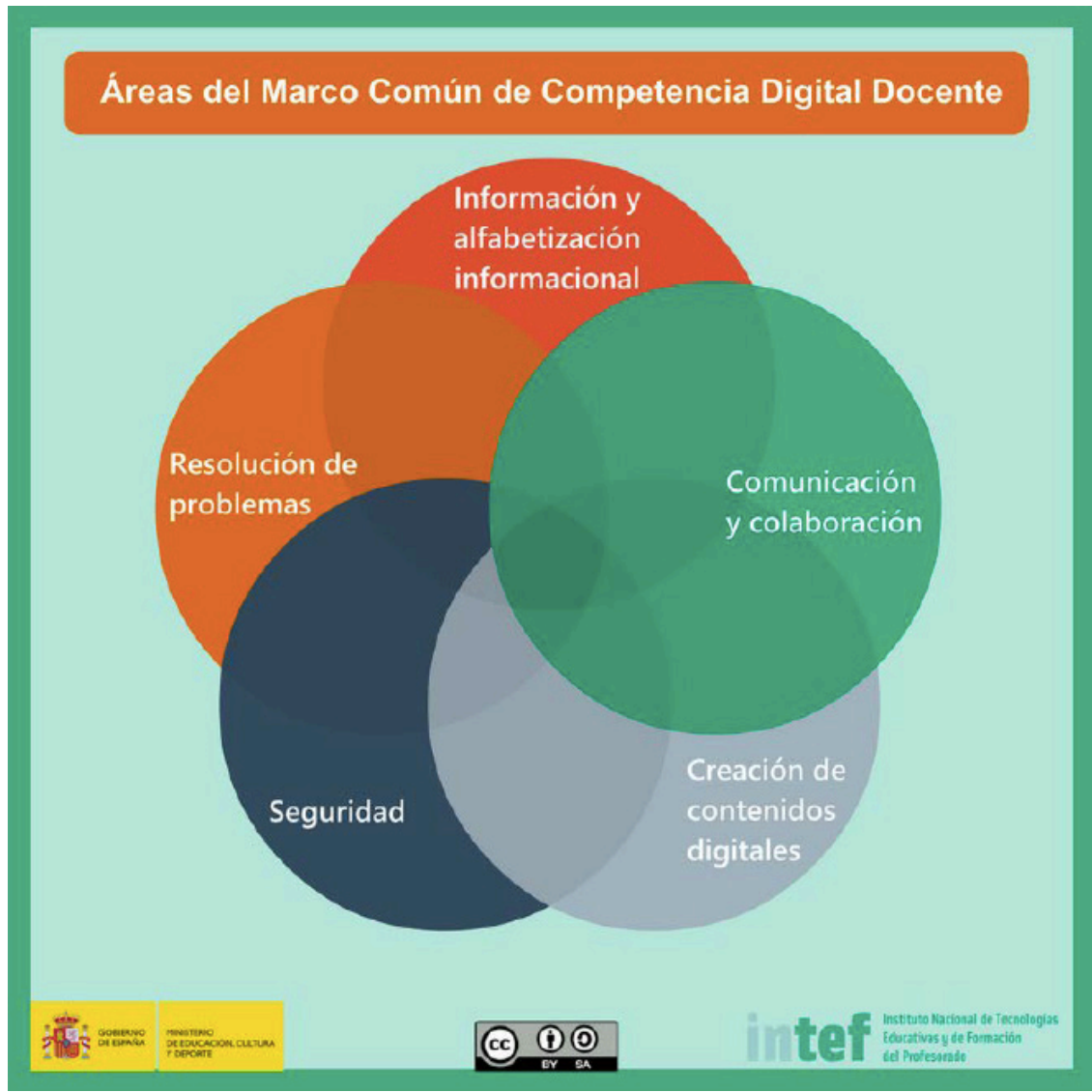

Fonte: INTEF (2017).

Ainda na Europa, é de destacar o projeto Mentoring Technology-Enhanced Pedagogy (MENTEP), que foi desenvolvido entre 2015 e 2018, com envolvimento de onze mil professores e onze países europeus (Chipre, República Checa, Estónia, Finlândia, França, Grécia, Itália, Lituânia, Portugal, Eslovénia e Espanha), coordenado pela European Schoolnet, que desenvolveu uma ferramenta de autoavaliação online gratuita para professores, a Technology Enhanced Teaching Self-assessment Tool (TET-SAT), que propõe competências organizadas em dimensões e níveis de progressão. Ao promover a autorreflexão dos professores, oferece devolutivas individualizadas para apoiar processos de desenvolvimento de competências a partir da identificação de suas necessidades formativas. A 
ferramenta avalia quatro dimensões de competências pedagógicas digitais: 1) Pedagogia Digital, 2) Utilização e Produção Digital, 3) Comunicação e Colaboração Digital e 4) Cidadania Digital. As dimensões possuem quinze subáreas e trinta competências.

Figura 4 - Dimensões da TET-SAT

\section{Pedagogia Digital}

- Planejamento e implementação de estratégias de ensino usando TICs (Projeto de Aprendizagem)

- Projetar e gerenciar ambientes de aprendizagem baseados em TICS

- Avaliação apoiada pelas TICs

Colaboração e Comunicação Digital

- Comunicação usando tecnologias

e mídias sociais

- Participação on-line

- Colaboração com TICs

- Colaboração por meio das TICs
Proteção e Uso de Recursos Digitais

- Seleção e uso de recursos digitais

- Produção criativa

- Copyright e licenças

- Programação

\section{TET-SAT}

\section{Cidadania Digital}

- Comportamento on-line

- Gerenciamento da identidade digital

- Proteção do dispositivo

- Saúde e meio ambiente

Fonte: Abbiati et al. (2018).

Cada subárea contempla uma ou mais competências, as quais são descritas de acordo com cinco níveis de progressão: Inexperiente, Principiante, Autônomo, Experiente e Especialista. 
Figura 5 - Níveis de progressão da TET-SAT

\begin{tabular}{|c|c|c|c|c|c|}
\hline & INEXPERIENTE & PRINCIPIANTE & AUTÔNOMO & EXPERIENTE & ESPECIALISTA \\
\hline Descrição & \begin{tabular}{|l} 
Inexperiente \\
no uso da \\
tecnologia no \\
processo peda- \\
gógico
\end{tabular} & $\begin{array}{l}\text { Utilização } \\
\text { recente da } \\
\text { tecnologia no } \\
\text { processo peda- } \\
\text { gógico }\end{array}$ & $\begin{array}{l}\text { Consegue utili- } \\
\text { zar tecnologia } \\
\text { no processo } \\
\text { pedagógico }\end{array}$ & $\begin{array}{l}\text { Desenvolve o } \\
\text { processo pe- } \\
\text { dagógico com } \\
\text { tecnologia }\end{array}$ & $\begin{array}{l}\text { Especialista a } \\
\text { utilizar tecnolo- } \\
\text { gia no processo } \\
\text { pedagógico }\end{array}$ \\
\hline Uso das TIC & $\begin{array}{l}\text { Nunca ou rara- } \\
\text { mente }\end{array}$ & Básico & Autónomo & Experiente & $\begin{array}{l}\text { Criativo e } \\
\text { transformador }\end{array}$ \\
\hline $\begin{array}{l}\text { Práticas } \\
\text { Pedagógicas }\end{array}$ & $\begin{array}{l}\text { Raramente/ } \\
\text { nunca suporta- } \\
\text { das pelas TIC }\end{array}$ & $\begin{array}{l}\text { As mesmas } \\
\text { práticas supor- } \\
\text { tadas pelas TIC }\end{array}$ & $\begin{array}{l}\text { TIC usadas } \\
\text { como ferra- } \\
\text { mentas para } \\
\text { desenvolver } \\
\text { práticas básicas }\end{array}$ & $\begin{array}{l}\text { TIC utilizadas } \\
\text { para modificar/ } \\
\text { melhorar as } \\
\text { práticas }\end{array}$ & $\begin{array}{l}\text { Novas práticas } \\
\text { só possíveis } \\
\text { com recurso } \\
\text { às TIC }\end{array}$ \\
\hline $\begin{array}{l}\text { Impacto no } \\
\text { Processo }\end{array}$ & $\begin{array}{l}\text { Manutenção } \\
\text { de práticas }\end{array}$ & Substituição & Aumento & Modificação & Transformação \\
\hline
\end{tabular}

Fonte: Abbiati et al. (2018).

Atualmente a TET-SAT está traduzida para dezesseis línguas e mantém uma comunidade de cooperação e pesquisa ao seu redor, gerando estudos sobre os resultados e lançando novas oportunidades de aprimoramento das competências digitais de professores na Europa (ABBIATI et al., 2018).

Finalmente, destaque também para o projeto desenvolvido em 2017, com o objetivo de orientar os estados membros da Comunidade Europeia no uso de tecnologias digitais para melhorar e inovar a educação e a formação, o modelo Digital Competence of Educators (DigCompEdu) (2017) - em português Competências Digitais de Professores -, é composto por seis áreas, sintetizadas na figura 6. 
Figura 6 - Modelo DigCompEdu

COMPETENNCIAS PROFISSIONAIS DOS PROFESSORES
COMPETÊNCIAS PEDAGÓGICAS DOS PROFESSORES
COMPETENNCIAS DOS ESTUDANTES

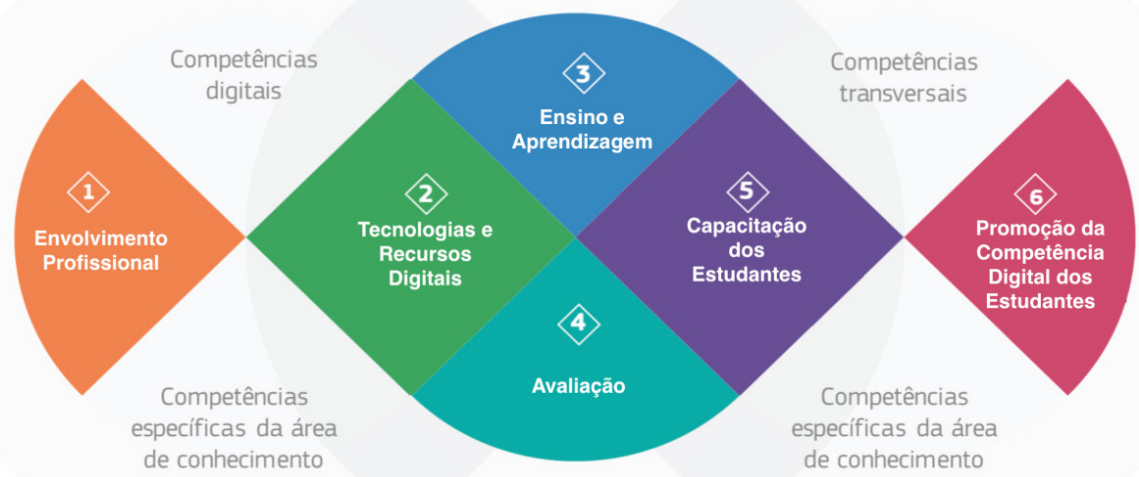

Fonte: Dias-Trindade, Moreira e Nunes (2019; traduzido e adaptado de Redecker e Punie, 2017).

A primeira área - Envolvimento Profissional - procura identificar as competências do professor no que diz respeito ao uso de tecnologias digitais para comunicar, colaborar e evoluir profissionalmente.

A segunda área- Tecnologias e Recursos Digitais- diz respeito à utilização de tecnologias e recursos digitais, especificamente, à capacidade de as usar, partilhar e proteger.

A terceira área - Ensino e Aprendizagem - refere-se à capacidade de os professores identificarem as suas capacidades para gerirem e organizarem o uso de tecnologias digitais no processo de ensino e de aprendizagem.

A quarta área - Avaliação - refere-se às competências na avaliação, concretamente na forma como são usadas as tecnologias digitais para melhorar o processo de avaliação dos estudantes.

A quinta área - Capacitação dos Estudantes - remete para a capacidade de utilizar as tecnologias digitais para aumentar a inclusão, personalização e o envolvimento ativo dos estudantes no ensino.

E a sexta área-Promoção da Competência Digital dos Estudantes - diz respeito às competências docentes para auxiliar os estudantes a usar tecnologias digitais de forma criativa e responsável. 
A partir dessas seis áreas, são detalhadas vinte e duas competências e seis níveis progressivos de apropriação das TDICs pelos professores, do nível iniciante ao nível inovador. Nessa perspetiva, nos dois primeiros níveis - Recém-chegado (A1) e Explorador (A2) -, o professor assimila novas informações e desenvolve práticas digitais básicas. Nos níveis intermediários - Integrador (B1) e Especialista (B2) -, aplica os conhecimentos desenvolvidos, buscando expandir e aprimorar suas práticas. Nos mais avançados - Líder (C1) e Pioneiro (C2) -, o professor aplica e compartilha seus conhecimentos, analisam práticas existentes e desenvolvem novas.

Quadro 3 - Níveis de apropriação das TDIC

\begin{tabular}{|c|c|}
\hline NÍVEL & CARACTERÍSTICA \\
\hline $\begin{array}{l}\text { RECÉM- } \\
\text { CHEGADO }\end{array}$ & $\begin{array}{l}\text { É consciente do potencial das TDIC para melhorar suas práticas } \\
\text { pedagógicas e profissionais. No entanto tem muito pouco contato } \\
\text { com tecnologias e as utiliza basicamente para preparar atividades } \\
\text { e para administração ou comunicação organizacional. Precisa de } \\
\text { orientação e encorajamento para expandir seu repertório e aplicar suas } \\
\text { competências digitais na área pedagógica. }\end{array}$ \\
\hline EXPLORADOR & $\begin{array}{l}\text { É consciente do potencial das TDIC e está interessado em explorá-las } \\
\text { para melhorar suas práticas pedagógicas. Já começou a usar tecnologias } \\
\text { digitais, sem, no entanto, seguir uma abordagem consistente. Precisa } \\
\text { de encorajamento, ideias e inspirações, como exemplos e orientação } \\
\text { de colegas. }\end{array}$ \\
\hline INTEGRADOR & $\begin{array}{l}\text { Experimenta TDIC em uma variedade de contextos e propósitos, } \\
\text { integrando-as a suas práticas. Utiliza as TDIC de forma criativa, para } \\
\text { melhorar diversos aspetos de seu desenvolvimento profissional. Busca } \\
\text { expandlr seu repertório de práticas, porém ainda está aprendendo } \\
\text { quais ferramentas funcionam melhor, em que situações, e como } \\
\text { adequar as TDIC às estratégias e aos métodos pedagógicos. Precisa } \\
\text { de tempo de experimentação e reflexão, complementado por } \\
\text { encorajamento colaborativo e intercâmbio de conhecimentos, para se } \\
\text { tornar especialista. }\end{array}$ \\
\hline ESPECIALISTA & $\begin{array}{l}\text { Usa uma variedade de TDIC com confiança, criatividade e criticidade } \\
\text { para aprimorar suas atividades profissionais. Seleciona tecnologias de } \\
\text { acordo com a situação e tenta entender as vantagens e as desvantagens } \\
\text { das diferentes estratégias digitais. Tem curiosidade e está aberto a novas } \\
\text { ideias, sabe que há muitas coisas que ainda não experimentou. Usa a } \\
\text { experimentação como meio de expandir, estruturar e consolidar seu } \\
\text { repertório de estratégias. É a espinha dorsal de qualquer organização } \\
\text { educacional quando se trata de práticas inovadoras. }\end{array}$ \\
\hline
\end{tabular}




\begin{tabular}{|c|l|}
\hline NÍVEL & \multicolumn{1}{|c|}{ CARACTERÍSTICA } \\
\hline LíDER & $\begin{array}{l}\text { Tem uma abordagem consistente e abrangente sobre o uso de TDIC } \\
\text { para melhorar a prática pedagógica. Conta com um amplo repertório } \\
\text { de estratégias com o uso de TDIC, e escolhe a mais adequada, de } \\
\text { acordo com a situação. Reflete continuamente sobre suas práticas e } \\
\text { as desenvolve, realiza trocas com os colegas e atualiza-se sobre novas } \\
\text { possibilidades e ideias. É uma fonte de inspiração e compartilha seus } \\
\text { conhecimentos. }\end{array}$ \\
\hline PIONEIRO & $\begin{array}{l}\text { Questiona a adequação das práticas pedagógicas contemporâneas, das } \\
\text { quais é líder. Preocupa-se com as restrições ou desvantagens dessas } \\
\text { práticas, sentindo- se motivado a inovar ainda mais na educação. } \\
\text { Experimenta TDIC altamente inovadoras e complexas e/ou desenvolve } \\
\text { novas abordagens pedagógicas. Além de liderar a inovação, é um } \\
\text { modelo para os demais professores. }\end{array}$ \\
\hline
\end{tabular}

Fonte: European Comission (2017).

Por considerarmos que este é um modelo muito completo, que oferece devolutivas individualizadas para apoiar processos de desenvolvimento de competências a partir da identificação das necessidades formativas identificadas e, também, por existir já um estudo em Portugal desenvolvido por Dias-Trindade, Moreira e Nunes (2019) que validou as qualidades psicométricas do questionário desenvolvido pelo Serviço de Ciência e Conhecimento da Comissão Europeia decidimos, pois, desenvolver a nossa pesquisa com este modelo e com esta escala de autoavaliação de competências digitais de professores no Brasil.

\section{ASPETOS METOdOLÓGICOS DA PESQUISA}

Na perspetiva teórica e metodológica da investigação, a importância que recai no campo de formação de professores e das tecnologias em educação, a mesma justifica-se pela necessidade de:

- Construir uma agenda de pesquisa com esse foco para os próximos dez anos na Bahia;

- Fomentar a criação de uma rede de solidariedade da pesquisa, no sentido de ampliá-la para outros Estados brasileiros;

- Identificar, descrever as pesquisas, que porventura já existam, com esse objetivo no cenário brasileiro; 
- Apresentar fundamentos teóricos que subsidiem a ampliação dos estudos nesse campo da pesquisa educacional no ensino superior;

- Fomentar e promover intercâmbios de discussões, pesquisas, práticas de formação acerca do domínio da pesquisa no cenário nacional e internacional (já iniciadas com a Universidade de Coimbra, Universidade Aberta de Portugal, Universidade do Estado da Bahia, Universidade Federal da Bahia e Universidade Federal do Recôncavo da Bahia);

- Potencializar produções acadêmico-científicas em parceria Brasil-Portugal, no sentido de difundir os estudos e esforços da construção de um diagnóstico ampliado acerca do objeto investigado;

- Fortalecer as relações entre os países de língua portuguesa e latino-americanos no campo das pesquisas relacionadas a fluência e proficiência digital e das competências tecnopedagógicas dos professores;

- Mapear e socializar possíveis estratégias e indicadores de efetivação de propostas de formação de professores do ensino superior para atender as demandas do Século XXI para a educação, principalmente, no âmbito das instituições universitárias envolvidas da Bahia.

Como já referido, esta pesquisa, tem como objetivo apresentar as discussões iniciais do projeto em curso, desenvolvido pela Rede Colaborativa de Aprendizagem (RCA), no que diz respeito aos referenciais e ao modelo utilizado para a avaliação do nível de proficiência digital de professores do Ensino Superior da Bahia, e consequente definição das diferentes trilhas de aprendizagem a criar em função do nível de proficiência diagnosticado.

Para tanto, propõe-se:

a) mapear o contexto de acesso e utilização das TIC no cenário do ensino superior público baiano;

b) analisar as peculiaridades contextuais tecnológicas de cada região do Estado, a partir das necessidades de formação dos professores, para identificar as convergências, equivalências e disparidades existentes quanto às possibilidades de atuação docente por território de identidade;

c) construir um descritivo teórico-crítico das demandas de formação de professores universitários para o contexto tecnológico digital e apresentar propostas de ações e/ou políticas de formação a serem implementadas, para qualificação dos docentes das instituições de Ensino Superior envolvidas. 
Tendo, pois, em consideração o contexto descrito, propomos uma pesquisa que irá conjugar em termos metodológicos, dois tipos de investigação: a qualitativa e a quantitativa com o objetivo de investigar um "fenômeno contemporâneo dentro de seu contexto da vida real" (YIN, 2005, p. 21).

A opção por essa combinação metodológica, justifica-se, sobretudo, porque uma pesquisa que procura analisar a constituição de representações profissionais deve flexibilizar-se nas suas práticas metodológicas e desenvolver estratégias de abordagem diferenciadas que permitam desenvolver um processo completo de inquirição procurando o sentido mais profundo das conceções dos professores, dos seus discursos o que não é totalmente possível apenas com um instrumento quantitativo. Na realidade uma forma de tornar a investigação mais consistente é através da triangulação, isto é, da combinação de metodologias quantitativas e qualitativas no estudo dos mesmos fenómenos. Assim, num primeiro momento, e situando-se num quadro de um paradigma construtivista, a investigação firma-se numa metodologia de cariz qualitativo.

Esse tipo de metodologia, contrapondo-se a uma visão mecanicista e reducionista da ciência que exclui as noções de liberdade e de individualidade, põe a tónica na revalorização da "pessoa", como sujeito de conhecimento capaz de refletir, de racionalizar, de comunicar e de interagir (PUJADAS MUNOZ, 1992). De acordo com Eisner (1991), o entendimento do eu como um instrumento é precisamente uma das características das metodologias qualitativas, na perspetiva de que é o eu que se envolve nas situações e lhes institui um sentido e uma representação. Essa instauração de representações e sentidos constitui leituras interpretativas em busca da compreensão, tanto da parte dos sujeitos do estudo, como da parte de quem investiga, inevitavelmente condicionado pela sua história pessoal e pelos seus valores (GREENE, 1999).

Habitualmente considera-se que um processo completo de inquirição deve começar por uma fase qualitativa, sob a forma de um conjunto de entrevistas não diretivas ou estruturadas, seguindo-se uma fase quantitativa. Igualmente entende-se que a aplicação de um questionário a uma amostra permite uma inferência estatística através da qual se verificam os resultados da primeira fase (GHIGLIONE; MATALON, 2001). Assim, num segundo momento, e partindo da análise de um quadro categorial empírico e teórico existente na área, irão ser aplicados ques- 
tionários aos professores com o intuito de avaliar o nível de proficiência digital de professores do Ensino Superior da Bahia.

A pesquisa tem como campo o Estado da Bahia, no Brasil, espaço de formação superior que se localiza em todo o Estado, com uma aderência geográfica de vinte e quatro municípios, espalhados geograficamente por todas as regiões do Estado, onde se localiza a UNEB; em mais três municípios no território de identidade do Recôncavo Baiano, onde estão os campi da UFRB e na capital do Estado, Salvador, um dos campi da UFBA, portanto apresenta-se como uma realidade de atuação docente no ensino superior que pode corresponder a um diagnóstico do próprio Estado da Bahia.

Assim, com o objetivo de avaliar o nível de proficiência digital dos professores do Ensino Superior do Estado da Bahia, no ES, irá ser administrado, e como já referido, o questionário de autoavaliação online, desenvolvido pelo Serviço de Ciência e Conhecimento da Comissão Europeia (EU Science Hub) e validado por Dias-Trindade, Moreira e Nunes (2019) para a população portuguesa, e adaptado para o português do Brasil por Sales e Santo (ver Anexo 1), apontando-Ihes sugestões para a melhoria de sua prática educativa.

Antes da aplicação do questionário, será necessário por parte da RCA compor o corpus teórico que fundamentará a pesquisa, a partir de estudos internacionais, discussões, e imersão no universo da pesquisa realizada em Portugal, nomeadamente com os estudos desenvolvidos com o DigCompEdu (DIAS-TRINDADE; MOREIRA, 2018). E, após a administração da escala de autoavaliação, será realizada a análise, interpretação dos dados e informações, para construção do perfil de fluência e proficiência tecnopedagógicas dos professores do ES do Estado da Bahia e, finalmente, a composição das trilhas de aprendizagem em função dos resultados alcançados, a serem construídas coletivamente pelos pesquisadores envolvidos na RCA e desenvolvidos nas instituições que são campo de trabalho nessa primeira etapa do projeto.

Vale ainda acrescentar que a pesquisa seguirá para aprovação do Comitê de Ética de Pesquisa com Seres Humanos, em atendimento às normas brasileiras de pesquisa na área de Ciências Humanas e Sociais e, após a aprovação, iniciaremos o trabalho de campo. 


\section{CONSIDERAÇÕES FINAIS}

Quer a nível nacional, quer internacional, o crescimento da perceção de que os professores devem acompanhar a evolução digital e capacitar-se para a utilização das tecnologias digitais tem sido uma realidade.

Conscientes dessa necessidade, várias organizações e centros internacionais, como a Sociedade Internacional para a Tecnologia em Educação, a Organização das Nações Unidas para Educação, Ciência e Cultura da UNESCO, o Instituto Nacional de Tecnologías Educativas y de Formación del Profesorado (INTEF- Espanha), o Centro de Inovação para a Educação Brasileira (CIEB) ou o EU Science Hub, departamento da União Europeia que se dedica à identificação das necessidades dos professores ao nível das competências digitais, têm vindo a realizar diferentes relatórios para apoiar e sustentar o trabalho desenvolvido nessa área.

Da análise que realizámos aos modelos desenvolvidos por essas organizações, a qual constituiu a primeira fase desta pesquisa no seio da RCA, destacou-se o relatório DigCompEdu (REDECKER, 2017) que se configura como um excelente referencial para a definição de um instrumento de avaliação das competências digitais dos professores. Por considerarmos que este é um modelo integrador, inovador e de qualidade, que oferece devolutivas individualizadas para apoiar processos de desenvolvimento de competências digitais a partir da identificação das necessidades formativas identificadas e, também, por existir já um estudo desenvolvido por Dias-Trindade, Moreira e Nunes (2019) em língua portuguesa que validou as qualidades psicométricas do questionário desenvolvido pelo Serviço de Ciência e Conhecimento da Comissão Europeia, decidimos, pois, desenvolver a nossa pesquisa com esse referencial e com essa escala de autoavaliação de competências digitais de professores no Brasil.

Assim, com esta pesquisa, desenvolvida pela RCA, pretendemos, por um lado, avaliar o desenvolvimento das competências digitais dos professores e, por outro, possibilitar a criação de trilhas de aprendizagem para os professores, adequadas ao nível de proficiência dos profissionais de educação e ainda a criação de comunidades de práticas profissionais, de conteúdos que promovam a excelência na educação. 
Figura 7 - Objetivos Rede Colaborativa de Aprendizagem (RCA)

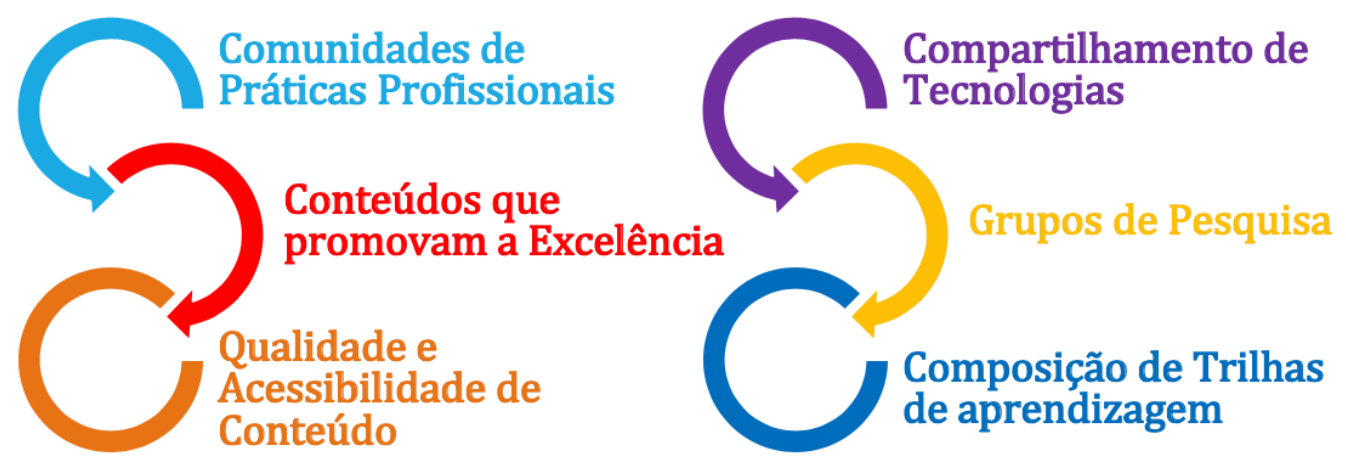

Fonte: SEAD, UFBA (2019).

E para isso será necessário:

- o fortalecimento das relações institucionais entre Brasil e Portugal para fins de ampliação da pesquisa;

- a realização de ações de troca e cooperação internacional para difusão e produção de conhecimentos na área;

- o planejamento e efetivação de cursos de formação continuada (extensão universitária) propostos para os docentes do ES a partir dos resultados da pesquisa;

- a publicação de produções científicas em periódicos indexados, de modo individual e em conjunto com os parceiros;

- apresentar às instituições de ES participantes da pesquisa um mapa das demandas de formação continuada de professores universitários, possibilitando a efetivação de ações que proponham o desenvolvimento de competências para uma fluência digital coerente com a sociedade em rede em quer nos encontramos.

Assim, podemos iniciar um processo em que auxiliemos aos professores do ES a enfrentar as demandas que passam por rápidas mudanças e que exigem abordagens educacionais cada vez mais ampliadas, potencializando no Brasil a constituição de uma rede de formação que, também, tenha os mesmos objetivos do DigCompEdu de ajudar a orientar as políticas e de adaptar e implementar políticas e práticas regionais e nacionais de formação, que possam auxiliar diretamente nas questões mais emergentes e comuns entre as regiões do país, 
bem como contribuir com o diálogo e o intercâmbio de melhores práticas entre fronteiras.

Mesmo com as limitações expostas por Figueiredo (2017, p. 32) acerca do DigCompEdu, buscamos não criar "visões simplificadas e mecanicistas da educação e da formação, [esquecendo] o caráter complexo e eminentemente humano" das realidades investigadas, pois consideraremos, nesta investigação, as especificidades materiais, humanas, geográficas e educacionais de cada território de identidade na construção do mapa diagnóstico do perfil de fluência digital e proficiência tecnopedagógica dos professores do ES da Bahia, pois, como destaca este autor, "por muito forte que seja o componente digital do mundo de hoje, não vivemos num mundo digital: vivemos num mundo analógico e digital, uno e indivisível" (FIGUEIREDO, 2017, p. 32), portanto, numa sociedade da convergência e de proposições de modelos híbridos de formação.

\section{REFERÊNCIAS}

ABBIATI, G.; AZZOLINI, D.; PIAZZALUNGA, D.; RETTORE, E.; SCHIZZEROTTO, A. MENTEP Evaluation report, results of the field trials: the impact of the technology-enhanced selfassessment tool (TET-SAT). Bruxelas, Bélgica: European Schoolnet, FBK- IRVAPP, 2018.

BAUMAN, Z. Modernidade líquida. Tradução de Plínio Dentzein. Rio de Janeiro: Zahar, 2001.

CARRETERO, S.; VUORIKARI, R.; PUNIE, Y. DigComp 2.1: The Digital Competence Framework for Citizens with eight profi-ciency levels and examples of use. Luxembourg: Publications Office of the European Union, 2017. doi: 10.2760/38842

CIEB. Competências para educadores e multiplicadores para uso de TIDCs. Nota técnica n. 8. São Paulo: Centro de Inovação para a Educação Brasileira, 2019.

DIAS-TRINDADE, S.; MOREIRA, J. A.; NUNES, C. Escala de Avaliação de competências digitais de professores. Procedimentos de construção e validação. Texto Livre. Linguagem e Tecnologia, v. 12, n. 2, p. 152-71, maio/ago. 2019. Disponível em: http://www.periodicos. letras.ufmg.br/index.php/textolivre/article/view/14921

DIAS-TRINDADE, S.; MOREIRA, J. A. Avaliação das competências e fluência digitais de professores no ensino público médio e fundamental em Portugal. Revista Diálogo Educacional, Curitiba, v. 18, n. 58, p. 624-44, jul./set. 2018. Disponível em: https:// periodicos.pucpr.br/index.php/dialogoeducacional/article/view/24187. DOI: http://dx.doi. org/10.7213/1981-416X.18.058.DS02 
EISNER, E. The enlightened eye: Qualitative inquiry and enhancement of educational practice. New Jersey, EUA: Prentice-Hall, 1991.

EUROPEAN COMISSION. European Framework for the Digital Competence of Educators DigCompEdu. JRC science for policy report. REDECKER, C.; PUNIE, Y (Ed). Joint Research Centre (JRC). Luxemburgo: Publications Office of the European Union, 2017. Disponível em: https://ec.europa.eu/jrc/en/digcompedu. Acesso em: jun. 2019.

EUROPEAN COMISSION. Self assessment tool: TET-SAT. Bruxelas: Mentep (Mentoring Technology-Enhanced Pedagogy), 2018. Disponível em: <http://mentep.eun.org/tet-sat>. Acesso em: junho de 2019.

FIGUEIREDO, A. D. Referenciais de Competências Digitais: uma análise. Dirigir \& Formar, Portugal, n. 17, p. 31-3, out./dez. 2017.

GHIGLIONE, R.; MATALON, B. O inquérito - teoria e prática. Oeiras, Portugal: Edições Celta, 2001.

GREENE, M. Um filósofo olha para a investigação qualitativa. Revista de Educação, Lisboa, Vol. VIII, n. 1, p. 3-14, 1999.

INTEF. Marco Común de Competencia Digital Docente. 2017. Disponível em: http:// educalab.es/documents/10180/12809/Marco+competencia+digital+docente+2017/ afb07987-1ad6-4b2d-bdc8-58e9faeeccea

ISTE. ISTE Standarts. 2017. Disponível em: https://www.iste.org/standards. Acesso em: 15 jun. 2019.

ISTE. ISTE Standards for Teachers. 2008. Disponível em: http://www.iste.org/standards/ standards-for-teachers. Acesso em: 15 jun. 2019.

LAVE, J.; WENGER, E. Situated learning: legitimate peripheral participation. Cambridge: Cambridge University Press, 1991.

OECD. Innovating education and educating for innovation. The power of digital technologies and skills. 2016. Disponível em: https://www.oecd.org/education/innovating-educationand-educating-for-innovation-9789264265097-en.htm. Acesso em: 15 jun. 2019.

PISA. PISA 2015 Results. Excellence and Equity in Education. 2016. Disponível em https:// www.oecd.org/education/pisa-2015-results-volume-i-9789264266490-en.htm. Acesso em: 15 jun. 2019. 
PUJADAS MUNOZ, J. El método biográfico: el uso de las histórias de vida en ciências sociales. Madrid: CIS, 1992.

REDECKER, C. European framework for the Digital Competence of Educators (DigCompEdu). Luxembourg: Publications Office of the European Union, 2017. Disponível em: https:// publications.europa.eu/en/publication-detail/-/publication/fcc33b68-d581-11e7-a5b901aa75ed71a1/language-en. Acesso em: jun. 2019.

SEAD, UFBA. VI SEMINÁRIO INTERNACIONAL DE EDUCAÇÃO A DISTÂNCIA DA UFBA - TECNOLOGIAS EDUCACIONAIS E INOVAÇÃO. 2019. Disponível em: http://www. seminarioead.ufba.br/. Acesso em: jun. 2019.

SALES, M. V. S. Tecnologias e formação: práticas curriculares em experiências inovadoras no ensino superior. In: HETKOWSKI, T. M.; RAMOS, M. A. (Org.). Tecnologias e processos inovadores na educação. Curitiba: CRV, 2016.

UNESCO. ICT competency standards for teachers: implementation guidelines. Paris: UNESCO, 2008.

YIN, R. Estudo de caso: planejamento e métodos. Porto Alegre: Bookman, 2005.

\section{Sobre os autores:}

Mary Valda Sales: Doutora em Educação pela Universidade Federal da Bahia (UFBA). Mestra em Educação e Contemporaneidade pela Universidade do Estado da Bahia (UNEB). Licenciada em Pedagogia pela Universidade Católica de Salvador (UCSal). Coordenadora do Programa de Pós-Graduação em Educação e Contemporaneidade (PPGEduC), Professora Adjunta da UNEB, Departamento de Educação - Campus I (Salvador), atuando na graduação e na pós-graduação (Mestrado e Doutorado). Líder do grupo de pesquisa ForTEC, pesquisadora do Núcleo de Estudos de Pedagogia do Ensino Superior (NEPES) sedeado no CEIS20. Pesquisadora em Educação, Tecnologias, Currículo e Formação, com enfâse na Educação a Distância, Processos Tecnológicos, Mediação Pedagógica, Desenho Didático de Cursos. Tem experiência em formação de formadores, gestão e desenvolvimento de cursos a distância, elaboração de currículos de cursos, produção e avaliação de material didático. E-mail: marysales@uneb.br, Orcid: http://orcid.org/0000-0002-9488-0103 
José António Marques Moreira: Doutor e Mestre em Ciências da Educação pela Universidade de Coimbra. Pós-Doutoramento em Tecnologias Educacionais e da Comunicação também pela Universidade de Coimbra. Licenciatura em História da Arte pela Faculdade de Letras da Universidade de Coimbra. Professor Auxiliar no Departamento de Educação e Ensino a Distância (DEED) da Universidade Aberta (UAb). Diretor da Delegação Regional do Porto da Universidade Aberta e Coordenador da Unidade de Desenvolvimento dos Centros Locais de Aprendizagem (UMCLA) da mesma universidade. Coordenador Científico da Unidade Móvel de Investigação em Estudos do Local (ELO) e investigador no Centro de Estudos Interdisciplinares do Século XX (CEIS20) da Universidade de Coimbra e no Laboratório de Educação a Distância e eLearning (LE@d) da UAb. Coordenador do Núcleo de Estudos de Pedagogia do Ensino Superior (NEPES) sedeado no CEIS20. E-mail: jmoreira@uab.pt, Orcid: http://orcid.org/0000-0003-0147-0592

Márcia Rangel: Mestre em Gestão de Tecnologias Educacionais pela Universidade Estadual da Bahia (UNEB), Especialista em Gestão de Sistema pela Universidade Federal da Bahia (UFBA), Graduada em Administração pela Universidade Católica de Salvador (UCSal). Superintendente de Educação a Distância da UFBA e Coordenadora da Universidade aberta do Brasil na UFBA. E-mail: mrangel.ufba@gmail.com, Orcid: http://orcid.org/0000-0002-6116-6421

\section{Recebido em março de 2019 Aprovado em agosto de 2019}




\title{
ANEXO
}

\section{Escala de Autoavaliação de Competências Digitais de Professores}

\author{
Dias-Trindade, Moreira e Nunes (2019)
}

(Tradução português do Brasil-Mary Valda Souza Sales e Eniel do Espírito Santo, 2019)

Para cada uma das 21 afirmações que se seguem, deve selecionar apenas a opção que considera mais adequada.

\begin{tabular}{|l|l|}
\hline \multicolumn{1}{|l|}{ 1. Uso diferentes canais de comunicação para diferentes objetivos. } \\
\hline & Nunca uso canais de comunicação digitais. \\
\hline & Uso de forma básica canais de comunicação digitais como o email, por exemplo. \\
\hline $\begin{array}{l}\text { Por vezes combino canais de comunicação. Uso, por exemplo o email, a website da } \\
\text { instituição, blog etc. }\end{array}$ & $\begin{array}{l}\text { Seleciono e combino diferentes soluções digitais para comunicar de forma mais } \\
\text { efetiva. }\end{array}$ \\
\hline Reflito, discuto e desenvolvo de forma proativa as minhas estratégias de comunicação. \\
\hline
\end{tabular}

2. Uso tecnologias e recursos digitais para trabalhar com colegas dentro e fora da minha instituição.

Raramente tenho oportunidade de colaborar com outros professores.

As vezes troco materiais com colegas (por exemplo via email).

Trabalhamos em conjunto, entre colegas, em ambientes colaborativos ou usamos pastas compartilhadas.

Troco frequentemente ideias e materiais, com professores externos à minha instituição, por exemplo em redes de professores online ou num ambiente colaborativo de trabalho.

Elaboro materiais em conjunto com outros professores numa rede digital online de professores de diferentes instituições.

3. Considero como, quando e porquê usar tecnologias digitais na sala de aula, para garantir que sejam usadas potencialmente.

\begin{tabular}{l|l|}
\hline Nunca ou raramente uso tecnologias digitais na sala de aula. \\
ou pro um uso básico dos equipamentos disponíveis, por exemplo quadros brancos \\
\hline Uso uma variedade de recursos e ferramentas digitais nas aulas. \\
\hline Uso ferramentas digitais para melhorar de forma sistemática o processo de ensino. \\
\hline Uso ferramentas digitais para implementar estratégias pedagógicas inovadoras.
\end{tabular}




\section{Uso tecnologias digitais para permitir que os estudantes planejem, documentem e acompanhem as suas aprendizagens de forma autônoma. \\ Não é possível no ambiente de trabalho. \\ Os estudantes refletem sobre as suas aprendizagens, mas não com tecnologias digitais. \\ Às vezes uso questionários online para autoavaliação. \\ Uso diferentes ferramentas digitais para os estudantes planejarem, documentarem ou refletirem sobre as suas aprendizagens. \\ Integro de forma sistemática diferentes ferramentas digitais que permitam aos estudantes planejar, acompanhar e refletir sobre os seus progressos.}

5. Analiso a informação disponível regularmente para identificar os estudantes que precisam de apoio adicional.

Não aplicável: esta informação não está disponível e/ou não é da minha responsabilidade analisá-la.

Parcialmente. Só analiso a informação acadêmica relevante. Por exemplo desempenho e níveis de aprendizagem.

Também considero informação sobre as atividades dos estudantes e o comportamento para identificar estudantes que precisam de apoio adicional.

Verifico de forma regular as evidências para identificar estudantes que precisam de apoio adicional.

Analiso de forma sistemática a informação e intervenho regularmente.

6. Utilizo tecnologias digitais para fornecer aos estudantes atividades adaptadas aos níveis e necessidades individuais de aprendizagem.

Não aplicável: No ambiente de trabalho todos os estudantes devem fazer as mesmas atividades, independentemente do seu nível.

Apresento aos estudantes atividades diferentes, mas uso formatos não digitais.

Para alguns: apresento atividades digitais para aqueles que estão ou avançados ou atrasados.

Por nível: diferentes grupos de competências recebem diferentes tarefas digitais.

Apresento a cada estudante um conjunto de tarefas digitais adaptadas às suas necessidades individuais de aprendizagem.

7. Desenvolvo continuamente as minhas competências de uso das ferramentas digitais.

Raramente tenho oportunidade de desenvolver as competências digitais para ensinar.

Melhoro as competências através de reflexão e experimentação.

Uso um conjunto de recursos para desenvolver as competências digitais para ensinar.

Discuto com os colegas sobre como usar as tecnologias digitais para inovar e melhorar a prática educativa.

Ajudo os colegas a desenvolver as suas estratégias digitais no processo de ensino. 


\begin{tabular}{|c|}
\hline $\begin{array}{l}\text { 8. Utilizo diferentes softwares e mecanismos de segurança para proteger conteúdo } \\
\text { pessoal. }\end{array}$ \\
\hline Não é aplicável. A instituição ocupa-se disto. \\
\hline Não é aplicável: não guardo dados pessoais de forma eletrônica. \\
\hline Em alguns casos protejo, mas não de forma consistente. \\
\hline Protejo os documentos com senhas. \\
\hline $\begin{array}{l}\text { Protejo cuidadosamente os arquivos. Por exemplo, senhas difíceis com codificação } \\
\text { e frequentes atualizações de software. }\end{array}$ \\
\hline
\end{tabular}

9. Acompanho as atividades dos estudantes nos ambientes colaborativos online que usamos.

\begin{tabular}{|l|l|}
\hline \multicolumn{2}{l|}{ que usamos. } \\
\hline & Não aplicável: não uso ambientes digitais com os estudantes. \\
\hline & Respeito as suas criações e não verifico nem interfiro. \\
\hline & De vez em quando verifico o que eles fazem e as discussões. \\
\hline & Verifico e analiso regularmente as atividades online dos estudantes. \\
\hline & Intervenho regularmente com comentários motivadores ou corretivos. \\
\hline
\end{tabular}

10. Uso ferramentas de avaliação digital, ou testes e jogos, para verificar o desenvolvimento dos estudantes e fornecer feedback mais eficiente.

Não aplicável: no ambiente de trabalho não acompanho o desenvolvimento dos estudantes.

Não é possível: Acompanho regularmente o desenvolvimento dos estudantes, mas não com avaliações ou tarefas digitais.

Às vezes uso ferramentas digitais para acompanhar o desenvolvimento dos estudantes.

Uso uma variedade de ferramentas digitais para acompanhar o desenvolvimento dos estudantes.

Uso sistematicamente diferentes ferramentas digitais para acompanhar 0 desenvolvimento dos estudantes.

11. Quando elaboro tarefas digitais para os estudantes, considero e procuro auxiliálos nos problemas que possam ter com os recursos digitais.

Não aplicável: não solicito trabalhos digitais.

Os estudantes não enfrentam esses problemas.

Adapto a tarefa para minimizar possíveis problemas.

Discuto possíveis obstáculos com os estudantes e em conjunto estudamos soluções.

Permito a variedade: adapto a tarefa, discuto soluções e forneço formas alternativas de completar a tarefa. 


\section{Oriento os estudantes como verificar se a informação é confiável e a identificar informação errada ou contraditória através de notícias falsas. \\ Isto não é possível na disciplina ou no ambiente de trabalho. \\ Por vezes lembro aos estudantes que nem toda a informação online é de confiança. \\ Explico-Ihes como distinguir entre fontes confiáveis e não confiáveis. \\ Discuto com os estudantes como verificar a veracidade das informações. \\ Sempre: discutimos como a informação é gerada e como pode ser distorcida. \\ 13. Participo, sempre que possível, de formação online.

\begin{tabular}{|l|l}
\hline & É uma nova área que ainda não considerei. \\
\hline & Até agora não, mas estou interessado(a). \\
\hline & Muito raramente. \\
\hline & Já experimentei várias oportunidades de formação online. \\
\hline & Participo frequentemente em diferentes tipos de formação online. \\
\hline
\end{tabular}

14. Quando os estudantes trabalham em grupo, usam tecnologias digitais para gerar e documentar os dados que apresentam.

Não aplicável: os estudantes não trabalham em grupos.

Não aplicável: não é possível integrar tecnologias digitais nos trabalhos de grupo.

Incentivo os estudantes que trabalham em grupos a procurar informação online ou a apresentar os resultados num formato digital.

Solicito aos estudantes trabalhar em grupo e que usem a internet e apresentem os resultados num formato digital.

Os estudantes trocam evidências e, em conjunto, constroem conhecimento num espaço online colaborativo onde acompanho o progresso.

\section{Uso as tecnologias digitais para fornecer feedback efetivo.}

Não aplicável: não está previsto o feedback no ambiente de trabalho.

Forneço frequentemente feedback mas não em formato digital.

Às vezes uso meios digitais para dar feedback aos estudantes.

Uso uma variedade de meios digitais para fornecer feedback. Por exemplo por meio das respostas erradas em questionários, comentários nos trabalhos, etc

Uso de forma regular ferramentas digitais para dar feedback aos estudantes.

16. Elaboro atividades que possibilitem aos estudantes usar meios digitais para comunicação e colaboração, uns com os outros ou com o público externo.

\begin{tabular}{|l|l|}
\hline & Isto não é possível no meu ambiente de trabalho. \\
\hline & Só faço isso em raras ocasiões. \\
\hline & Os estudantes só usam os meios digitais para comunicarem entre si. \\
\hline & Os estudantes usam para comunicar uns com os outros e com um público externo. \\
\hline $\begin{array}{l}\text { De forma sistemática, permito que os estudantes aumentem progressivamente as } \\
\text { suas competências. }\end{array}$ \\
\hline
\end{tabular}




\section{Procuro diferentes sítios web e estratégias para pesquisar e selecionar recursos educacionais digitais. \\ Raramente uso a Internet para pesquisar recursos. \\ Uso sítios de busca e plataformas educativas para encontrar recursos relevantes. \\ Avalio e seleciono recursos com base na sua adequação para os estudantes. \\ Comparo recursos usando uma variedade de critérios relevantes, por exemplo qualidade, adequação, confiança,etc. \\ Sugiro e oriento os colegas sobre recursos e estratégias de busca adequados. \\ 18. Uso tecnologias digitais para desenvolver metodologias ativas. \\ No ambiente de trabalho não é possível envolver de forma ativa os estudantes. Envolvo os estudantes ativamente, mas não com tecnologias digitais. \\ Ao ensinar, uso estímulos motivadores, por ex. vídeos, animações, desenhos animados, etc. \\ Os estudantes, frequentemente, trabalham com tecnologias digitais nas aulas. \\ Os estudantes usam sistematicamente tecnologias digitais para investigar, discutir e construir conhecimento.}

19. Ensino os estudantes a se comportar de forma segura e responsável online. Isto não é possível na disciplina ou no ambiente de trabalho.

Informo que precisam ser cuidadosos com a disponibilização de informação pessoal online.

Explico as regras de conduta básicas para atuar de forma segura e responsável em ambientes digitais.

Discutimos e acordamos quais as regras de conduta.

Sistematicamente: os estudantes aplicam regras existentes e habituais nos diferentes ambientes digitais que usam.

20. Elaboro atividades de aprendizagem que implicam a criação de conteúdos digitais. Por exemplo, vídeos, áudio, fotos, apresentações digitais, blogs, wikis, etc.

Isto não é possível na disciplina ou no ambiente de trabalho.

É difícil implementar isto com os estudantes.

Às vezes, como atividade voluntária ou adicional.

Os estudantes criam conteúdo digital como parte integrante dos seus estudos.

Isto é uma parte integrante dos seus estudos e com um crescente nível de dificuldade para desenvolver cada vez mais as suas competências.

21. Incentivo os estudantes a usar tecnologias digitais de forma criativa para resolver problemas concretos.

Isto não é possível na disciplina ou no ambiente de trabalho.

Só muito raramente tenho oportunidade de implementar resolução de problemas digitais. Ocasionalmente, sempre que surge uma oportunidade.

Muitas vezes experimentamos soluções tecnológicas digitais para resolver problemas que surgem.

Integro sistematicamente oportunidades de uso criativo de tecnologias digitais na resolução de problemas. 